\title{
Interval cancers after skin cancer screening: incidence, tumour characteristics and risk factors for cutaneous melanoma
}

\begin{abstract}
J Hübner ${ }^{\star}, 1$, A Waldmann ${ }^{1}$, A C Geller ${ }^{2}$, M A Weinstock ${ }^{3,4,5}$, N Eisemann ${ }^{1}$, M Noftz ${ }^{1}$, S Bertram ${ }^{1}, S_{\text {Nolte }}^{6,7}$, B Volkmer ${ }^{8}$, R Greinert $^{8}$, E Breitbart ${ }^{9}$ and A Katalinic ${ }^{1,10}$

${ }^{1}$ Institute for Social Medicine and Epidemiology, University of Lübeck, Ratzeburger Allee 160, Lübeck 23562, Germany; ${ }^{2}$ Department of Social and Behavioral Sciences, Harvard T.H. Chan School of Public Health, 677 Huntington Avenue, Boston, MA 02115, USA; ${ }^{3}$ Center for Dermatoepidemiology, VA Medical Center-111D, 830 Chalkstone Avenue, Providence, RI 02908, USA; ${ }^{4}$ Department of Dermatology, Rhode Island Hospital, 593 Eddy Street, Providence, RI 02903, USA; ${ }^{5}$ Departments of Dermatology and Epidemiology, Brown University, 593 Eddy Street, Providence, RI 02903, USA; ${ }^{6}$ Department of Psychosomatic Medicine, Center for Internal Medicine and Dermatology, Charité-Universitätsmedizin Berlin, Charitéplatz 1, Berlin 10117, Germany; ${ }^{7}$ Population Health Strategic Research Centre, Deakin University, 221 Burwood Highway, Melbourne, VIC 3125, Australia; ${ }^{8}$ Division of Molecular Cell Biology, Dermatology Center, Elbe Clinics Stade-Buxtehude, Am Krankenhaus 1, Buxtehude 21614, Germany; ${ }^{9}$ Association of Dermatological Prevention e.V., Cremon 11, Hamburg 20457, Germany and ${ }^{10}$ Cancer Registry of Schleswig-Holstein, Ratzeburger Allee 160, Lübeck 23562, Germany
\end{abstract}

Background: The rate of interval cancers is an established indicator for the performance of a cancer-screening programme.

Methods: We examined the incidence, tumour characteristics and risk factors of melanoma interval cancers that occurred in participants of the SCREEN project, which was carried out 2003/2004 in Schleswig-Holstein, Germany. Data from 350306 SCREEN participants, who had been screened negative for melanoma, were linked to data of the state cancer registry. Melanoma interval cancers were defined as melanomas diagnosed within 4-24 months after SCREEN examination. Results were compared with melanomas of the pre-SCREEN era (1999-2002), extracted from the cancer registry.

Results: The overall relative incidence of melanoma interval cancers in terms of observed/expected ratio was 0.93 (95\% Cl: $0.82-$ 1.05; in situ: 1.61 (1.32-1.95), invasive: 0.71 (0.60-0.84)). Compared with melanomas of the pre-SCREEN era, the interval melanomas were thinner and had a slightly greater proportion of lentigo maligna melanomas whereas nodular melanomas were less frequent.

Interpretation: The results indicate a moderate performance of the SCREEN intervention with an excess of in situ melanomas. In part, the findings might be due to specifics of the SCREEN project, in particular a short-term follow-up of patients at high risk for melanoma.

Cutaneous melanoma (CM) causes around $90 \%$ of deaths from skin cancer (Garbe et al, 2012). The incidence has risen steadily worldwide over the last decades. As the tumour stage at diagnosis has a significant impact on the course of the disease, systematic skin cancer-screening programmes aimed at the early detection of melanomas might be a promising way to reduce melanoma mortality. However, conclusive evidence, as randomised controlled trials might provide, is lacking. A trial in Queensland, Australia, in which 9 of 18 communities were randomised to receive a melanoma screening programme (Lowe et al, 2004), was not

*Correspondence: Dr J Hübner; E-mail: Joachim.Huebner@uksh.de

Received 18 July 2016; revised 1 November 2016; accepted 3 November 2016; published online 29 November 2016

(c) 2017 Cancer Research UK. All rights reserved 0007-0920/17 
completed due to low funding. An updated systematic evidence review from the US Preventive Services Task Force (USPSTF) recently found only limited evidence for skin cancer screening, particularly on melanoma mortality (Wernli et al, 2016). On the basis of the review, the USPSTF does not recommend visual skin examination by a clinician to screen for skin cancer in asymptomatic adults (US Preventive Services Task Force, 2016). In Germany, a nationwide skin cancer early detection programme with whole-body skin examinations was implemented in 2008. The decision was based on the results of a preceding pilot project, which had been conducted in Schleswig-Holstein, Germany (SCREEN project: Skin Cancer Research to provide Evidence for Effectiveness in Northern Germany), between 2003 and 2004 (Breitbart et al, 2012). Following this project, a significant decline in melanoma mortality was observed in Schleswig-Holstein, whereas in the adjacent regions mortality rates were stable (Katalinic et al, 2012). Another registry-based study showed that after implementation of the SCREEN project, the regional incidence of advanced melanomas (TNM stages T2, T3 and for women also T4) decreased slightly, whereas thinner lesions (in situ and T1) occurred more frequently (Eisemann et al, 2014). On the other hand, within 5 years after implementation of the aforementioned German nationwide screening programme, no decline in melanoma mortality could be observed. In Schleswig-Holstein, the disease-specific mortality even rose between 2009 and 2013. It is unclear whether these observations data reflect an actual ineffectiveness of the current programme, which differs in some ways from the SCREEN project, or whether they are caused by too brief an observation period (Katalinic et al, 2015).

Following from these mixed findings, additional research is needed to gain more evidence for or against the value of population-based melanoma screening in view of its effect on mortality rates. In view of other cancer-screening programmes, such as breast cancer screening, a well-established performance indicator are cancers that are diagnosed in screened participants during the interval between a negative screening examination and the subsequent regular screening (Perry et al, 2006). These socalled interval cancers comprise both malignancies that were present at the time of the preceding screening examination but were not detected, and those that have developed during the interval ('true' interval cancers). An effective screening programme should result in fewer interval cancers than to be expected in the absence of screening.
The objective of this study was to evaluate the performance of a population-based melanoma screening by applying the concept of interval cancers to the SCREEN project. There is a unique opportunity to study interval cancers since the SCREEN participants agreed to the linkage of their individual data to the population-based cancer registry.

\section{MATERIALS AND METHODS}

Data from the SCREEN project. The protocol of the SCREEN project has been reported in detail elsewhere (Breitbart et al, 2012). Within the project, residents of Schleswig-Holstein, the northernmost state of Germany, aged $\geqslant 20$ years and holding a statutory health insurance were offered a whole-body skin examination between July 2003 and June 2004. Participants were free to visit any physician who had qualified for the programme by completing a one-day training course. Of 1.88 million eligible residents, 360288 (19.1\%) participated in the SCREEN project. Part of the examination was the assessment of the following known risk factors for melanoma: personal or (first-degree) family history of $\mathrm{CM}, \geqslant 40$ common nevi ( $\geqslant 2 \mathrm{~mm}$ diameter), $\geqslant 1$ clinically atypical nevi and $\geqslant 1$ congenital moles. In case of a non-dermatologist physician conducting the initial examination, the screenee was referred to a dermatologist if any risk factor was assessed or if a suspicious lesion was detected. Taking biopsy specimens for further histopathological work-up was reserved to dermatologists. Furthermore, dermatologists had the option to invite screenees for a follow-up examination within 3-36 months if they deemed surveillance to be advisable. Only the first CM per person was counted and included in the analysis.

Data from the population-based cancer registry of SchleswigHolstein. Since 1998, all physicians in Schleswig-Holstein report incident malignancies to the state cancer registry. Registration of invasive melanomas is assumed to be complete (that is, $\geqslant 95 \%$ ) in Schleswig-Holstein since 1999 (Katalinic et al, 2003). Data include person-related information (for example, date and place of residence) and information on the tumour (for example, date of diagnosis, ICD-code, histological type, tumour stage and body site).

Study population. Within the SCREEN cohort comprising 360288 participants, 585 persons had been diagnosed with

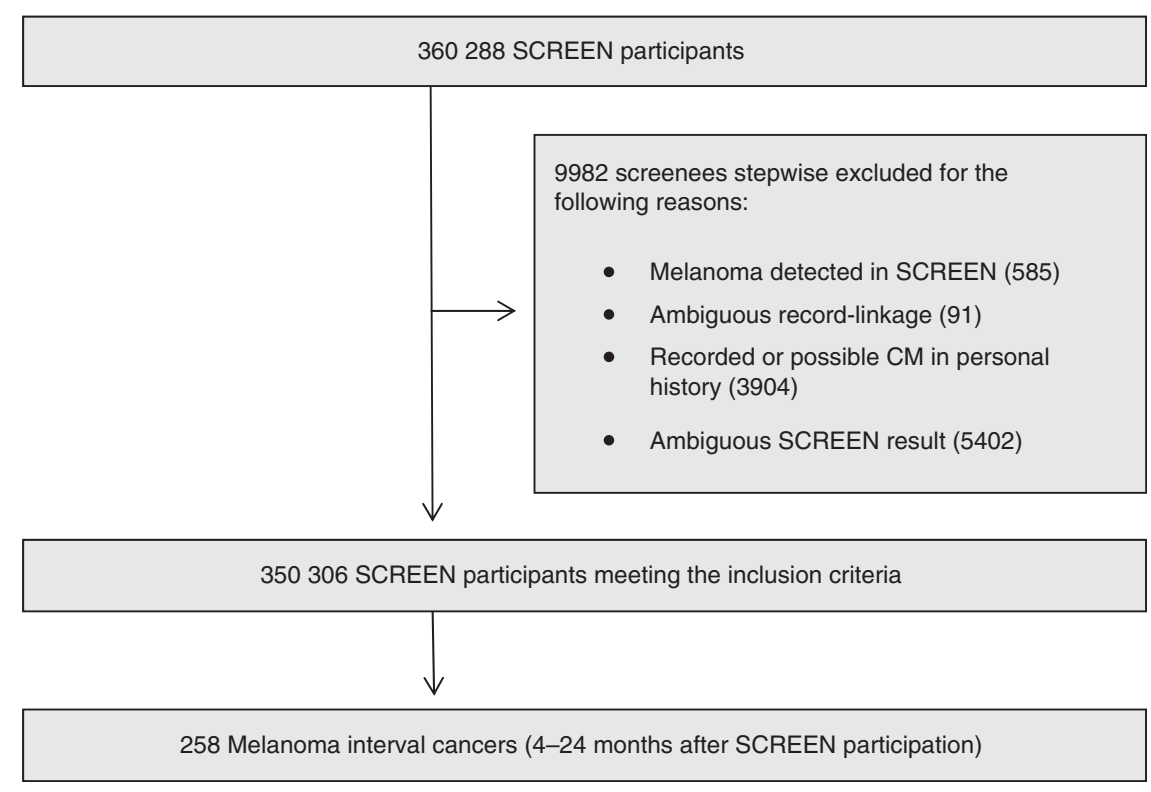

Figure 1. Flow chart of the study population. 
melanoma. These persons were not included in the analysis since, by definition, interval cancers occur only in participants with negative screen results. The remaining subpopulation was linked to cancer registry data using a probabilistic record linkage, which has been described in detail elsewhere (Obi et al, 2010). In principle, the matching uses any personal information, which is contained in both the SCREEN data and the cancer registry. In contrast to a deterministic linkage that postulates exact correspondence of these data, the probabilistic approach tolerates small differences taking into account their statistical significance. Uncertain matches, which failed to be confirmed manually (ambiguous linkage results), were excluded. For this analysis, we also excluded persons with a prior history of melanoma as the cancer registry usually only registers the first incident melanoma. Furthermore, participants without definite screening results were excluded from the analysis, that is, screenees with clinical suspicion of skin cancer for whom no histopathological report was documented. The remaining 350306 participants with a negative initial screening result were deemed at risk for a melanoma interval cancer (Figure 1).

Melanoma interval cancers and screening interval. Melanoma interval cancers were defined as in situ or invasive CM (ICD-10: D03 and C43) that were diagnosed during a follow-up time of 4-24 months after an initial negative screening and were recorded in the cancer registry. Melanomas that were diagnosed within $0-3$ months after screening were not classified as interval cancers as, in these cases, diagnoses have likely been triggered by the SCREEN procedure even if histopathological confirmed findings were not documented as part of the SCREEN project. The SCREEN project was a one-off screening, with examinations scheduled generally only once for each participant during the one-year project period. In accordance with the current nationwide skin cancer-screening programme (Choudhury et al, 2012), we set 24 months as an applicable interval length.

Data analysis. Descriptive statistics of the study population are presented using frequencies and percentages by sex and in total regarding age, risk factors and recommendation for follow-up. The number of observed interval cancers by time, sex and invasive status was calculated. In addition, the corresponding number of expected melanomas in absence of screening was estimated using age- and sex-specific background incidence for melanoma from the pre-SCREEN era 1999-2002, following the European guidelines for breast cancer screening (Perry et al, 2006). An alternative way would have been to extract background incidence from other German states where no screening has been offered. That method was not chosen because a regional characteristic of SchleswigHolstein would have been passed over. Long-term data demonstrate that the melanoma incidence in Schleswig-Holstein is higher than in other German states from early times of cancer registration (Association of Population-based Cancer Registries in Germany (GEKID), 2016). We calculated the relative incidence in terms of observed/expected ratio with 95\% confidence intervals (CI) (Sahai and Khurshid, 1993), with a result of $<1$ indicating fewer melanomas than expected. Absolute and relative frequencies of interval melanomas and melanomas of the pre-SCREEN era are displayed by sex and in total regarding age, histological type, tumour size (T-category of TNM classification), anatomic site and risk factors (the latter for interval melanomas only). The relative incidence of large tumours (defined as T3 or T4) was calculated as described above.

We used logistic regression to identify risk factors for interval melanomas. Crude as well as sex- and age-adjusted odds ratios (OR) with 95\% CI were calculated for aforementioned melanoma risk factors. A fully adjusted model was fitted to identify independent risk factors. To explore the influence of the followup recommendation on the occurrence of interval melanomas, we conducted a post-hoc regression analysis using sex, age, risk status and the recommendation for follow-up (given/not given) as independent variables.

\section{RESULTS}

The characteristics of the 350306 participants who were defined at risk for a melanoma interval cancer are summarised in Table 1. Younger women are considerably overrepresented. Risk factors for CM were present in $23.4 \%$ of all cases. One-fifth of the study population $(21.5 \%)$ was recommended to reappear for a follow-up examination within 24 months after screening.

Frequency of melanoma interval cancers. Melanoma interval cancers were observed in 258 participants with a negative screen result (150 invasive and 108 in situ melanomas), giving an interval cancer rate of 73.6 per 100000 (invasive: 42.8 per 100000 ; in situ: 30.8 per 100000 ). Within 2 years after negative screening, 277.1 melanomas would be expected using the pre-SCREEN incidence (1999-2002), giving an observed/expected ratio of 0.93 (95\% CI: $0.82-1.05)$, whereas considerable differences resulted for in situ melanoma (1.61 (95\% CI: 1.32-1.95)) and invasive melanoma $(0.71$ (95\% CI: 0.60-0.84)) respectively. Within the 2 years, the incidence of both invasive and in situ melanoma increased with time.

Table 1. Description of participants of the SCREEN project with negative screening result

\begin{tabular}{|c|c|c|c|}
\hline & Women $(n=258660)$ & Men $(n=91646)$ & Total $(n=350306)$ \\
\hline Mean age, years (s.d.) & $482(16.1)$ & $538(15.7)$ & $496(16.2)$ \\
\hline \multicolumn{4}{|l|}{ Age group } \\
\hline $35-49$ years & 84358 (32.6\%) & 24467 (26.7\%) & 108825 (31.1\%) \\
\hline $50-64$ years & 68395 (26.4\%) & 28790 (31.4\%) & 97185 (27.7\%) \\
\hline$\geqslant 65$ years & $47691(18.4 \%)$ & $26793(29.2 \%)$ & 74484 (21.3\%) \\
\hline \multicolumn{4}{|l|}{ Risk factors } \\
\hline Any risk factor for $\mathrm{CM}$ & $59126(22.9 \%)$ & $22679(24.7 \%)$ & 81805 (23.4\%) \\
\hline Family history (first-degree) of CM & $4782(1.8 \%)$ & $1133(1.2 \%)$ & 5915 (1.7\%) \\
\hline Multiple common nevi & 31207 (12.1\%) & $13514(14.7 \%)$ & 44721 (12.8\%) \\
\hline Clinically atypical nevi & $27414(10.6 \%)$ & $11282(12.3 \%)$ & 38696 (11.0\%) \\
\hline Congenital moles & $15100(5.8 \%)$ & $4744(5.2 \%)$ & $19844(5.7 \%)$ \\
\hline \multicolumn{4}{|l|}{ Recommendation for follow-up ( $\leqslant 24$ months) } \\
\hline
\end{tabular}


The overall relative incidence in the second year after the screening was approximately twice as high as in the first year (Table 2).

Patient and tumour characteristics of interval cancers. In comparison to population-based incident melanoma cases in the pre-SCREEN period (Table 3), there were more in situ cancers among the interval cancers $(41.9 \%$ vs $22.5 \%)$. Information on tumour size (T-category of TNM) was available in $64.0 \%$ of the invasive interval cancers as opposed to $57.6 \%$ of the invasive melanomas recorded during the pre-SCREEN era. The distribution of the tumour sizes was more favourable in interval cancers (proportion of larger (that is, T3/T4) melanomas: $10 / 96=10.4 \%$ vs

Table 2. Relative melanoma interval cancer incidence (in situ and invasive) and $95 \%$ confidence intervals in terms of observed/ expected ratios

\begin{tabular}{|c|c|c|c|c|c|c|c|c|c|}
\hline & \multicolumn{3}{|c|}{ In situ } & \multicolumn{3}{|c|}{ Invasive } & \multicolumn{3}{|c|}{ Total } \\
\hline & Women & Men & Total & Women & Men & Total & Women & Men & Total \\
\hline Year 1 & $\begin{array}{c}24 / 26.0=0.92 \\
(0.59-1.37)\end{array}$ & $\begin{array}{c}10 / 7.5=1.34 \\
(0.64-2.45)\end{array}$ & $\begin{array}{c}34 / 33.5=1.02 \\
(0.70-1.42)\end{array}$ & $\begin{array}{c}29 / 73.6=0.39 \\
(0.26-0.57)\end{array}$ & $\begin{array}{c}24 / 31.4=0.76 \\
(0.49-1.14)\end{array}$ & $\begin{array}{c}53 / 105.1=0.50 \\
(0.38-0.66)\end{array}$ & $\begin{array}{c}53 / 99.6=0.53 \\
(0.40-0.70)\end{array}$ & $\begin{array}{c}34 / 38.9=0.87 \\
(0.61-1.22)\end{array}$ & $\begin{array}{c}87 / 138.5=0.63 \\
(0.50-0.77)\end{array}$ \\
\hline Year 2 & $\begin{array}{c}58 / 26.0=2.23 \\
(1.69-2.88)\end{array}$ & $\begin{array}{c}16 / 7.5=2.14 \\
(1.22-3.46)\end{array}$ & $\begin{array}{c}74 / 33.5=2.21 \\
(1.73-2.77)\end{array}$ & $\begin{array}{c}58 / 73.6=0.79 \\
(0.60-1.02)\end{array}$ & $\begin{array}{c}39 / 31.4=1.24 \\
(0.88-1.70)\end{array}$ & $\begin{array}{c}97 / 105.1=0.92 \\
(0.75-1.13)\end{array}$ & $\begin{array}{c}116 / 99.6=1.16 \\
(0.96-1.40)\end{array}$ & $\begin{array}{c}55 / 38.9=1.41 \\
(1.07-1.84)\end{array}$ & $\begin{array}{c}171 / 138.5=1.23 \\
(1.06-1.43)\end{array}$ \\
\hline Total & $\begin{array}{c}82 / 52.0=1.58 \\
(1.25-1.96)\end{array}$ & $\begin{array}{c}26 / 15.0=1.74 \\
(1.13-2.54)\end{array}$ & $\begin{array}{c}108 / 67.0=1.61 \\
(1.32-1.95)\end{array}$ & $\begin{array}{c}87 / 147.3=0.59 \\
(0.47-0.73)\end{array}$ & $\begin{array}{c}63 / 62,9=1.00 \\
(0.77-1.28)\end{array}$ & $\begin{array}{c}150 / 210.2=0.71 \\
(0.60-0.84)\end{array}$ & $\begin{array}{c}169 / 199.2=0.85 \\
(0.73-0.99)\end{array}$ & $\begin{array}{c}89 / 77.9=1.14 \\
(0.92-1.41)\end{array}$ & $\begin{array}{c}258 / 277.1=0.93 \\
(0.82-1.05)\end{array}$ \\
\hline
\end{tabular}

Table 3. Patient and tumour characteristics in interval melanomas and cases of the pre-SCREEN era

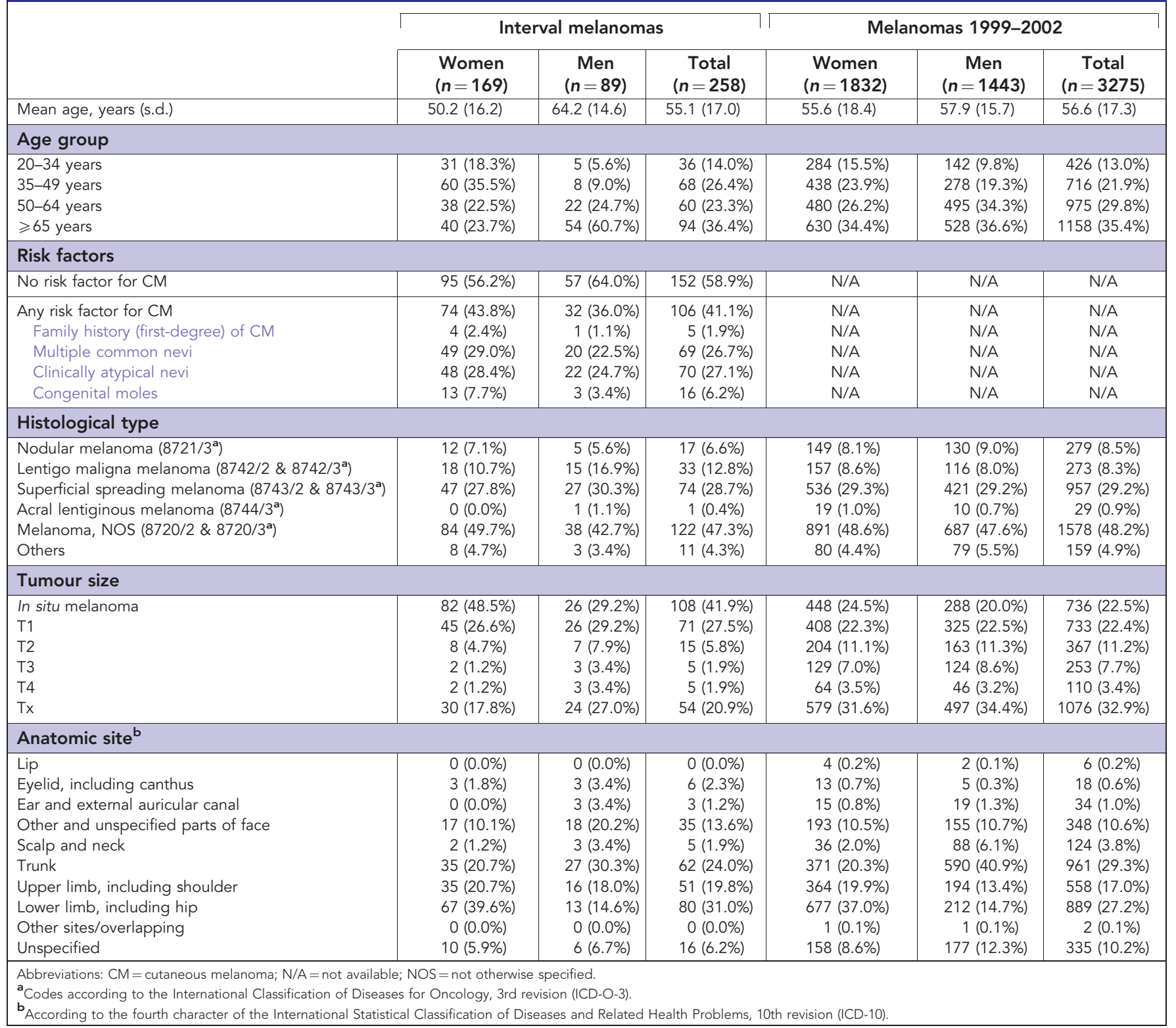


$363 / 1463=24.8 \%)$. The relative incidence of larger tumours (observed/expected ratio) was 0.33 (95\% CI: 0.18-0.62).

Information on histological types was registered in slightly more than half of the interval melanomas as well as in melanomas of the pre-SCREEN era (Table 3). Relative frequency of lentigo maligna melanomas was higher in interval melanomas than in those registered before the SCREEN project (12.8\% vs $8.3 \%$ ), whereas nodular melanomas were slightly underrepresented $(6.6 \%$ vs $8.5 \%)$. The percentage of superficial spreading melanomas was similar in both groups. Compared with the pre-SCREEN melanomas, interval melanomas were more frequently located at the eyelid, including canthus, whereas other anatomic sites were similar.

In $41.1 \%$ of all patients with an interval cancer, at least one risk factor for CM was present, whereas this only applied to $23.4 \%$ of the total SCREEN population as reported above. Clinically atypical nevi and multiple common nevi were the most frequently reported risk factors $(27.1 \%$ and $26.7 \%$, respectively). Univariate and multivariate OR for receiving a diagnosis of interval cancer within 24 months for the assessed risk factors are shown in Table 4. Clinically atypical nevi increased the risk for interval cancer by 2.7 (95\% CI: 2.0-3.7) and multiple common nevi by 2.2 (95\% CI: $1.6-$ $3.1)$ in the fully adjusted model. Family history of melanoma and congenital moles were not associated with melanoma interval cancer. The influence of male sex lost significance in the multivariate analysis. Elderly participants were more likely to be diagnosed with interval melanomas than younger ones (age group $\geqslant 65$ years: OR 3.4 (95\% CI: 2.3-5.1), reference: age group 20-34 years). Considering assessment of risk for any reason, the OR was 2.8 (95\% CI: 2.2-4.0) when adjusted for sex and age. An analogous analysis for interval melanomas of the second year after screening resulted in very similar OR, compared with those for the interval melanomas in total (not shown).

The proportion of screenees who had been recommended for follow-up within 24 months was $41.5 \%$ in the interval melanoma group and $21.5 \%$ in other screenees. The association between recommendation for follow-up and diagnosis of an interval melanoma was significant (OR 1.8 (95\% CI: $1.3-2.4)$ ). The scheduled follow-up intervals were shorter in the interval melanoma group (10.1 months $( \pm 4.1)$ vs 12.8 months $( \pm 5.1)$ ). Two-thirds $(67.8 \%)$ of the screenees with a recommendation for follow-up had at least one risk factor (vs $11.2 \%$ in others).

Table 4. OR and $95 \% \mathrm{Cl}$ for interval melanoma

\begin{tabular}{|c|c|c|c|}
\hline Predictive factor & $\begin{array}{l}\text { OR } \\
(95 \% \mathrm{Cl}) \\
\text { crude }\end{array}$ & $\begin{array}{c}\text { OR } \\
(95 \% \mathrm{Cl}) \\
\text { sex and } \\
\text { age } \\
\text { adjusted }\end{array}$ & $\begin{array}{l}\text { OR }(95 \% \mathrm{Cl}) \\
\text { full model }\end{array}$ \\
\hline \multicolumn{4}{|l|}{ Sex } \\
\hline $\begin{array}{l}\text { Women } \\
\text { Men }\end{array}$ & $\begin{array}{c}1 \\
1.5(1.2-1.9)\end{array}$ & $\begin{array}{c}1 \\
1.3(1.0-1.8)\end{array}$ & $\begin{array}{c}1 \\
1.2(0.9-1.6)\end{array}$ \\
\hline \multicolumn{4}{|l|}{ Age group } \\
\hline $\begin{array}{l}20-34 \text { years } \\
35-49 \text { years } \\
50-64 \text { years } \\
\geqslant 65 \text { years }\end{array}$ & $\begin{array}{c}1 \\
1.2(0.8-1.8) \\
1.2(0.8-1.9) \\
2.4(1.7-3.6)\end{array}$ & \begin{tabular}{c|}
1 \\
$1.2(0.8-1.8)$ \\
$1.1(0.8-1.7)$ \\
$2.3(1.6-3.4)$
\end{tabular} & $\begin{array}{c}1 \\
1.2(0.8-1.9) \\
1.5(1.0-2.2) \\
3.4(2.3-5.1)\end{array}$ \\
\hline \multicolumn{4}{|l|}{ Risk factors } \\
\hline $\begin{array}{l}\text { Family history (first-degree) of CM } \\
\text { Multiple common nevi } \\
\text { Clinically atypical nevi } \\
\text { Congenital moles } \\
\text { Any risk factor }\end{array}$ & $\begin{array}{l}1.2(0.5-2.8) \\
2.5(1.9-3.3) \\
3.0(2.3-4.0) \\
1.1(0.7-1.8) \\
2.3(1.8-2.9)\end{array}$ & $\begin{array}{l}1.3(0.5-3.1) \\
3.1(2.3-4.2) \\
3.6(2.7-4.7) \\
1.3(0.8-2.1) \\
2.8(2.2-4.0)\end{array}$ & $\begin{array}{l}1.1(0.4-2.6) \\
2.2(1.6-3.1) \\
2.7(2.0-3.7) \\
0.9(0.5-1.5) \\
\quad \text { N/A }\end{array}$ \\
\hline \multicolumn{4}{|c|}{ 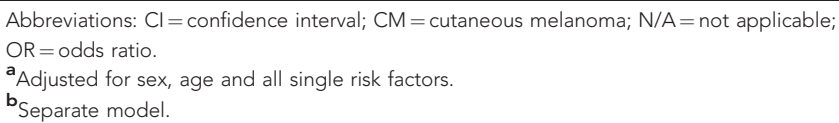 } \\
\hline
\end{tabular}

\section{DISCUSSION}

In an effective screening programme, the number of diagnosed cancers after negative screening should be lower than could be expected in the absence of screening. As regards breast cancer screening, the European Guidelines for Quality Assurance in Breast Cancer Screening and Diagnosis state a relative incidence of 0.4 as reference for a two-year interval (Perry et al, 2006). This means that in breast cancer screening, the observed incidence rate should be $60 \%$ lower than could be expected without screening. The observed incidence after the one-off skin cancer screening as part of the SCREEN project was only $7 \%$ lower than expected (observed/expected ratio 0.93). However, taking the invasiveness of interval melanomas into account, respective rates differ substantially. While invasive melanomas occurred less frequently by $29 \%$ (relative incidence: 0.71 ), indicating a moderate performance of SCREEN, the incidence of in situ melanomas was $61 \%$ higher than could be expected without screening. What are the most likely reasons for these unexpected results?

First, it has to be considered that the number of observed melanomas was calculated on the basis of melanoma incidence observed between 1999 and 2002, that is, a period of 4-5 years before the period during which the interval cancer melanomas occurred. This approach leads to a conservative estimate of the observed/expected ratio as from 1990 to 2007 the incidence rates for melanoma rose throughout Europe with estimated annual percentage changes of $3.8 \%$ ( $\pm 1.9 \%$ s.d.) in women and $4.2 \%$ $( \pm 1.8 \%)$ in men (Germany: $3.9 \%$ in women, $3.0 \%$ in men) (Arnold et al, 2014). We refrained from adjusting the expected number of interval melanomas by the increase in incidence because one reason, that might contribute to the apparent trend, is a growing completeness of registration (de Vries et al, 2003)-a development that supposedly does not come into effect in our data due to the given completeness of cancer registration in Schleswig-Holstein since 1999. Other possible reasons, however, such as a true increase of melanoma incidence, a raised awareness and improved diagnostic accuracy (Swerlick and Chen, 1997; Weyers, 2012), might well take effect in the SCREEN cohort. Second, individual risk factors for skin cancer and melanoma in particular, such as exposure to the sun, sunburns in childhood, use of tanning beds, skin type and nevi phenotype are subject to personal knowledge. The SCREEN project was accompanied by a communication intervention informing the general public about these factors (Anders et al, 2015). It can be assumed that individuals with such risk factors were more inclined to participate in the SCREEN project than others, making melanomas in SCREEN attendees more likely than in the general population (Breitbart et al, 2012). Third and most importantly, regular screening programmes provide examinations at fixed intervals; they generally do not allow for shortening of these intervals with respect to individual risk. In the SCREEN project, however, there was no routine follow up. Instead, dermatologists had the option to schedule a follow-up examination when they deemed surveillance to be advisable, for example, due to risk factors. We found that interval melanomas were more likely in screenees who had received a recommendation for follow up than in others. Additional re-examinations might have been self-initiated by individuals who may not have had any symptoms or signs, yet they were alerted to the risk of melanoma which had been triggered by their participation in SCREEN. Finally, a number of health insurances continued reimbursement of whole-body skin examinations after the SCREEN project-in some cases the minimal interval might have been shorter than 24 months. Thus, it can be assumed that, within 2 years after the SCREEN examination, a considerable number of examinations were induced, which would have been left to the subsequent regular screening in case of a 
continuous biennial programme. In other words, some of the 'interval melanomas' we observed were detected under circumstances that resemble a screening with focus on high risk persons.

The assumption of a hidden screening effect is strongly supported by the unexpectedly high incidence of in situ interval melanomas. An excess of in situ lesions is a common consequence of melanoma screening and cancer screening in general and may suggest a tendency toward overdiagnosis (Welch and Black, 2010). Some diagnoses of invasive interval melanomas, too, might be due to increased attention. Aitken et al report corresponding results of an Australian case-control study, investigating the impact of screening on subsequent invasive melanoma incidence. The proportion of cases who reported to have had a clinical skin examination within 3 years before the melanoma was first noticed (35.3\%) was higher than that of controls (28.3\%; based on a reference date) (Aitken et al, 2010). Taking these points into account, we assume that the incidence of both in situ and invasive melanoma interval cancers that we calculated clearly overestimates the occurrence of interval melanomas that might be expected in a long-lasting regular screening programme. Thus, a relative incidence of 0.71 for invasive melanoma interval cancers may be less discouraging as it appears at first glance. Furthermore, it should be noted that any effect of screening is necessarily limited in time. Looking at the frequency of interval melanomas in year 1 and year 2 after screening, it is possible that positive effects of participation in the SCREEN project disappear after only 12 months. Projected to a hypothesised annual screening, the relative incidence for invasive melanoma interval cancers improves to an estimated value of 0.50 .

The sole fact that the incidence of invasive melanoma decreased subsequent to screening is of limited value as this crude quantitative effect might potentially be thwarted by a bad prognosis of the interval cancers. Concerning SCREEN-detected lesions, it is a necessary consequence of early detection that their prognosis is systematically better than that of otherwise detected melanomas. However, this logic generally does not apply to interval cancers. Conceptually, they are likely to be fast growing tumours, passing from a state without detectable lesions at screening to a symptomatic disease within a relatively short time. In case of breast cancer screening, studies suggest that 'true' interval cancers are particularly large, biologically aggressive, and thus prognostically unfavourable cancers (van der Vegt et al, 2010; Heidinger et al, 2012). Tumour thickness is the most important prognostic factor in invasive melanoma. Compared with melanomas of the pre-SCREEN era, we observed a considerable shift to thinner tumours. Similar results were found in the aforementioned Australian case-control study. Therein screening reduced the risk of being diagnosed with a thick melanoma $(>0.75 \mathrm{~mm})$ by $\sim 14 \%$. For melanomas $\geqslant 3 \mathrm{~mm}$, the risk reduction was $\sim 40 \%$ (Aitken et al, 2010). Histologic type is another well-described prognostic factor in melanoma. A population-based study, covering $40 \%$ of Germany, found the most favourable 5-year relative survival in lentigo maligna melanoma (100.6\% in women and $100.0 \%$ in men), followed by superficial spreading melanoma ( $99.9 \%$ in women and $98.7 \%$ in men), acral lentiginous melanoma (95.0\% in women and $82.2 \%$ in men) and nodular melanoma (81.0\% in women and $70.9 \%$ in men). Five-year relative survival in all melanomas was 91.1\% in women and $87.0 \%$ in men (Eisemann et al, 2012). Applying these results, the prognoses of the interval melanomas appear to be better than those registered in the pre-SCREEN era.

Not surprisingly, occurrence of interval melanoma was significantly associated with older age. Age is a well-known risk factor for melanoma in both women and men, and the effect estimators we found are similar to those for SCREEN-detected melanomas (the authors, unpublished data). Multiple common nevi and presence of clinically atypical nevi, too, are well-known predictive features. Respective OR from our data are in good accordance with estimates that have been reported for melanoma in general (Gandini et al, 2005a; Chang et al, 2009; Olsen et al, 2010a). There is sufficient evidence regarding the predictive relevance of both family history and congenital moles (Rutter et al, 2004; Watt et al, 2004; Gandini et al, 2005b; Olsen et al, 2010 b). In our data, however, an independent association between these factors and interval melanoma could not be shown. We suspect that both selection bias and statistically significant although weak correlations between these factors and the confirmed predictors (multiple common nevi and clinically atypical nevi) might have led to this lack of an association.

To the best of our knowledge, this is the first study to evaluate the effectiveness of a population-based skin cancer-screening project applying the concept of interval cancer. A major strength of this study derives from the size of the negative screening cohort comprising more than 350000 screenees, documentation of potential risk factors and data linkage to a cancer registry with high completeness. The results indicate a moderate performance of the SCREEN project with an excess incidence of in situ melanomas following the initial examination. However, these observations have to be interpreted with caution. As discussed in detail, the number of interval melanomas is influenced by the particularities of the one-off SCREEN project. Therefore, generalisations, in particular projections to continuous screening programmes, are limited. Furthermore, frequency and characteristics of interval cancers are merely performance indicators of a screening programme; they cannot provide conclusive evidence for the effectiveness of a screening programme, which depends foremost on its capability to reduce mortality. Keeping these limitations in mind, the reduced incidence of invasive melanomas after the SCREEN project and the trend to favourable characteristics suggest a benefit rather than no effect, although this may be limited to the first year after screening. Further research is needed to confirm the results within the context of a continuous screening programme and to define adequate interval lengths according to risk status. Regulatory conditions that permit routine linkage of information on screening participation and epidemiological data are highly desirable.

\section{CONFLICT OF INTEREST}

The authors declare no conflict of interest.

\section{REFERENCES}

Aitken JF, Elwood M, Baade PD, Youl P, English D (2010) Clinical wholebody skin examination reduces the incidence of thick melanomas. Int J Cancer 126(2): 450-458.

Anders MP, Nolte S, Waldmann A, Capellaro M, Volkmer B, Greinert R, Breitbart EW (2015) The German SCREEN project-design and evaluation of the communication strategy. Eur J Public Health 25(1): 150-155.

Arnold M, Holterhues C, Hollestein LM, Coebergh JW, Nijsten T, Pukkala E, Holleczek B, Tryggvadottir L, Comber H, Bento MJ, Diba ChS, Micallef R, Primic-Zakelj M, Izarzugaza MI, Perucha J, Marcos-Gragera R, Galceran J, Ardanaz E, Schaffar R, Pring A, de Vries E (2014) Trends in incidence and predictions of cutaneous melanoma across Europe up to 2015. J Eur Acad Dermatol Venereol 28(9): 1170-1178.

Association of Population-based Cancer Registries in Germany (2016) Map of Cancer Incidence and Mortality in Germany (GEKID-Atlas).

Breitbart EW, Waldmann A, Nolte S, Capellaro M, Greinert R, Volkmer B, Katalinic A (2012) Systematic skin cancer screening in Northern Germany. J Am Acad Dermatol 66(2): 201-211.

Chang YM, Newton-Bishop JA, Bishop DT, Armstrong BK, Bataille V, Bergman W, Berwick M, Bracci PM, Elwood JM, Ernstoff MS, Green AC, Gruis NA, Holly EA, Ingvar C, Kanetsky PA, Karagas MR, Le Marchand L, Mackie RM, Olsson H, Osterlind A, Rebbeck TR, Reich K, Sasieni P, 
Siskind V, Swerdlow AJ, Titus-Ernstoff L, Zens MS, Ziegler A, Barrett JH (2009) A pooled analysis of melanocytic nevus phenotype and the risk of cutaneous melanoma at different latitudes. Int J Cancer 124(2): 420-428.

Choudhury K, Volkmer B, Greinert R, Christophers E, Breitbart EW (2012) Effectiveness of skin cancer screening programmes. Br J Dermatol 167(Suppl 2): 94-98.

de Vries E, Bray FI, Coebergh JW, Parkin DM (2003) Changing epidemiology of malignant cutaneous melanoma in Europe 1953-1997: rising trends in incidence and mortality but recent stabilizations in western Europe and decreases in Scandinavia. Int J Cancer 107(1): 119-126.

Eisemann N, Jansen L, Holleczek B, Waldmann A, Luttmann S, Emrich K, Hauschild A, Brenner H, Katalinic A (2012) Up-to-date results on survival of patients with melanoma in Germany. Br J Dermatol 167(3): 606-612.

Eisemann N, Waldmann A, Katalinic A (2014) Inzidenz des malignen Melanoms und Veränderung der stadienspezifischen Inzidenz nach Einführung eines Hautkrebsscreenings in Schleswig-Holstein. Bundesgesundheitsblatt Gesundheitsforschung Gesundheitsschutz 57(1): 7.

Gandini S, Sera F, Cattaruzza MS, Pasquini P, Abeni D, Boyle P, Melchi CF (2005a) Meta-analysis of risk factors for cutaneous melanoma: I. Common and atypical naevi. Eur J Cancer 41(1): 28-44.

Gandini S, Sera F, Cattaruzza MS, Pasquini P, Zanetti R, Masini C, Boyle P, Melchi CF (2005b) Meta-analysis of risk factors for cutaneous melanoma: III. Family history, actinic damage and phenotypic factors. Eur J Cancer 41(14): 2040-2059.

Garbe C, Peris K, Hauschild A, Saiag P, Middleton M, Spatz A, Grob JJ, Malvehy J, Newton-Bishop J, Stratigos A, Pehamberger H, Eggermont AM (2012) Diagnosis and treatment of melanoma. European consensus-based interdisciplinary guideline-update 2012. Eur J Cancer 48(15): 2375-2390.

Heidinger O, Batzler WU, Krieg V, Weigel S, Biesheuvel C, Heindel W, Hense HW (2012) The incidence of interval cancers in the German mammography screening program: results from the population-based cancer registry in North Rhine-Westphalia. Dtsch Arztebl Int 109(46): 781-787.

Katalinic A, Eisemann N, Waldmann A (2015) Skin cancer screening in Germany. Dtsch Arztebl Int 112(38): 629-634.

Katalinic A, Kunze U, Schafer T (2003) Epidemiology of cutaneous melanoma and non-melanoma skin cancer in Schleswig-Holstein, Germany: incidence, clinical subtypes, tumour stages and localization (epidemiology of skin cancer). Br J Dermatol 149(6): 1200-1206.

Katalinic A, Waldmann A, Weinstock MA, Geller AC, Eisemann N, Greinert R, Volkmer B, Breitbart E (2012) Does skin cancer screening save lives?: an observational study comparing trends in melanoma mortality in regions with and without screening. Cancer 118(21): 5395-5402.

Lowe JB, Ball J, Lynch BM, Baldwin L, Janda M, Stanton WR, Aitken JF (2004) Acceptability and feasibility of a community-based screening programme for melanoma in Australia. Health Promot Int 19(4): 437-444.
Obi N, Waldmann A, Babaev V, Katalinic A (2010) Abgleich einer großen Patientinnen-Kohorte aus der klinischen Praxis mit dem Krebsregister Schleswig-Holstein [record linkage of a large clinical practice patient cohort with the cancer registry Schleswig-Holstein]. Gesundheitswesen 73(7): 452-458.

Olsen CM, Carroll HJ, Whiteman DC (2010a) Estimating the attributable fraction for cancer: a meta-analysis of nevi and melanoma. Cancer Prev Res (Phila) 3(2): 233-245.

Olsen CM, Carroll HJ, Whiteman DC (2010b) Familial melanoma: a metaanalysis and estimates of attributable fraction. Cancer Epidemiol Biomarkers Prev 19(1): 65-73.

Perry N, Broeders M, de Wolf C, Törnberg S, Holland R, van Karsa L (2006) European Guidelines For Quality Assurance in Breast Cancer Screening and Diagnosis. 4th edn. European Communities 2006.

Rutter JL, Bromley CM, Goldstein AM, Elder DE, Holly EA, Guerry DT, Hartge P, Struewing JP, Hogg D, Halpern A, Sagebiel RW, Tucker MA (2004) Heterogeneity of risk for melanoma and pancreatic and digestive malignancies: a melanoma case-control study. Cancer 101(12): 2809-2816.

Sahai H, Khurshid A (1993) Confidence intervals for the mean of a poisson distribution. Biom J 35(7): 857-867.

Swerlick RA, Chen S (1997) The melanoma epidemic: more apparent than real? Mayo Clin Proc 72(6): 559-564.

US Preventive Services Task Force (2016) Screening for skin cancer. US Preventive Services Task Force Recommendation. JAMA 316(4): 429-435.

van der Vegt B, Wesseling J, Pijnappel RM, Dorrius MD, den Heeten GJ, de Roos MA, de Bock GH (2010) Aggressiveness of 'true' interval invasive ductal carcinomas of the breast in postmenopausal women. Mod Pathol 23(4): 629-636.

Watt AJ, Kotsis SV, Chung KC (2004) Risk of melanoma arising in large congenital melanocytic nevi: a systematic review. Plast Reconstr Surg 113(7): 1968-1974.

Welch HG, Black WC (2010) Overdiagnosis in cancer. J Natl Cancer Inst 102(9): 605-613.

Wernli KJ, Henrikson NB, Morrison CC, Nguyen M, Pocobelli G, Blasi PR (2016) Screening for skin cancer in adults: updated evidence report and systematic review for the US Preventive Services Task Force. JAMA 316(4): 436-447.

Weyers W (2012) The 'epidemic' of melanoma between under- and overdiagnosis. J Cutan Pathol 39(1): 9-16.

This work is published under the standard license to publish agreement. After 12 months the work will become freely available and the license terms will switch to a Creative Commons AttributionNonCommercial-Share Alike 4.0 Unported License. 